\title{
O estatuto do diagrama nos Elementos de Euclides ${ }^{1}$
}

\author{
The status of the diagram in Euclid's Elements
}

GÉRARD ÉMILE GRIMBERG

Universidade Federal do Rio de Janeiro | UFRJ

\begin{abstract}
RESUMO Este trabalho é o início de uma pesquisa relativa ao papel do diagrama na matemática grega. Nós estudamos o estatuto do diagrama nos Elementos de Euclides tentando situá-lo no contexto cultural e filosófico recorrendo em particular aos textos de Platão e Aristóteles que ressaltaram a imporância da relação entre visão e pensamento. Em um primeiro momento, tentamos definir o caráter semiótico e linguístico que reveste o diagrama em Euclides, seguindo a abordagem de Peirce. Em um segundo momento, analisamos como os diagramas têm as suas próprias regras sintáticas ligadas às significações que incorporam, o que confere aos diagramas uma função ideogramática. Finalmente ressaltamos a importância do diagrama no desempenho do chamado caráter formular da matemática grega e no estilo mesmo das proposições.
\end{abstract}

Palavras-chave história da matemática - diagramas matemáticos - representação geométrica na matemática.

\begin{abstract}
This work is the beginning of a study of the role of the diagram in Greek mathematics. We discuss the status of the diagram in Euclid's Elements trying to situate it in the cultural and philosophical context, using in particular the texts of Plato and Aristotle that stressed the relevant relationship between vision and thought. In a first time, we tried to define the semiotic and linguistic character of the Euclid's diagram, helping us of Peirce's approach. In a second time, we analyze how the diagrams have their own syntactic rules related to meanings that these incorporate, giving them an ideogramatic function. Finally, we emphasize the importance of the diagram in the so-called formular character of Greek mathematics and even the style of propositions.
\end{abstract}

Keywords history of mathematics - mathematical diagrams - geometrical representation.

\section{Introdução}

Tentar determinar o papel do diagrama nas proposições dos Elementos de Euclides remete a uma questão mais ampla: a questão da relação entre a visão e o pensamento discursivo na cultura grega em sua época. Sabemos a importância que reveste a matemática para a filosofia. De Zenão a Sexto Empiríco, os filósofos recorrem a exemplos matemáticos para ilustrar as suas problemáticas, alguns para afirmar a importância da matemática na busca da verdade, outros, como o último, para negar qualquer possibilidade de discurso verdadeiro. Mas a questão recíproca é apenas esboçada nos trabalhos de investigação da matemática grega, ou seja, a questão de saber como os outros domínios do saber grego estão envolvidos na elaboração do discurso matemático.

Esta problemática constitui uma tentativa de seguir o questionamento que vem encontrando o estudo da matemática grega desde 0 artigo de Sabetai Unguru² a saber a necessidade de reescrever a história da matemática grega. Mais recentemente, introduzindo um volume de Science in Context, Reviel Netz ${ }^{3}$ retoma a problemática de Unguru 
reavaliando a questão colocada. Netz relaciona a necessidade de reescrever a história de dois pontos de vista. 0 primeiro, historiográfico, defronta-se com a escassez das fontes, a mudança de perspectiva dos estudos (dos conceitos à análise das práticas), do texto ao contexto cultural. 0 segundo ponto de vista, corolário do primeiro, seria perguntar se "a ciência e a racionalidade dependem da percepção cultural (...), temos que mostrar, em termos de cultura, como

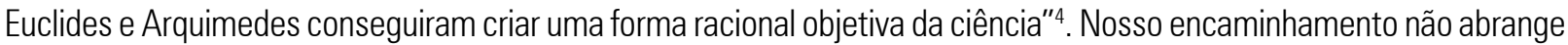
o fato cultural, mas unicamente o olhar de alguns gregos, em particular Aristóteles, sobre a consciência que eles têm, não apenas no que eles próprios chamam a matemática (a matemática enquanto disciplina é uma criação grega), mas também outras práticas como a poética, a retórica e a estética, que esclarecem o trabalho do matemático grego. Neste sentido, o nosso trabalho se encontra também na problemática de The Shaping of Deduction in Greek Mathematics de Netz $z^{5}$ que relaciona o papel do diagrama à dedução na matemática grega.

Pesquisar o estatuto do diagrama na matemática grega envolve logo, no entanto, vários aspectos do pensamento grego. A demonstração de uma proposição matemática frente a um público é um espetáculo. 0 matemático torna-se um ator, comentando a figura que implica todo um gestual, uma mímica apontando sobre o diagrama as hipóteses, combinando essas hipóteses tornadas visuais para desempenhar a demonstração. 0 matemático é também orador usando de retórica para tornar a demonstração convincente. 0 vocabulário mesmo do matemático é oriundo de termos relativos a objetos naturais, da técnica, da arquitetura, segundo Charles Mugler ${ }^{6}$, ou emprestados de outras ciências ou sistemas filosóficos ${ }^{7}$, o que confere ao discurso matemático uma dimensão metafórica e, portanto, poética. Além disso, a matemática define-se como o paradigma do discurso verdadeiro, e, enquanto tal, constitui a propedêutica de todas as outras ciências (Platão, Isócrates).

Não é, portanto, de se admirar que os outros domínios do saber tenham influenciado o destino da matemática grega. Neste intuito, procuramos esboçar um estudo dessa influência através da relação entre diagrama e discurso nos Elementos de Euclides.

Para isso três fontes parecem essenciais, os textos de Platão e Aristóteles (que precedem Euclides de meio século) e 0 comentário ${ }^{8}$ de Proclus sobre o livro I de Euclides que, apesar de ser um autor da antiguidade tardia, representa uma tradição de leitura de Euclides, assim como representa uma das fontes sobre a história da matemática pré-euclidiana. Consideramos este trabalho como um ponto de partida para um estudo mais amplo sobre outros escritos matemáticos. Todavia Euclides pode ser considerado como o horizonte que separa a história dos textos gregos matemáticos da préhistória. Com efeito, os Elementos são o primeiro texto matemático inteiro que chegou até nós. Este fato é a razão de começar nosso trabalho investigando o papel dos diagramas nos Elementos.

0 verbete ideîn em grego, além do primeiro significado (ver), designa várias atividades do pensamento: observar, representar-se, saber. Os nomes derivados da mesma raiz eîlos e idéa significam primeiro o aspecto exterior, a aparência, mas revestem ambos no vocabulário da filosofia vários significados importantes como a forma, a ideia ou a espécie, segundo o dicionário Bailly?.

No entanto, uma relação mais precisa entre 0 ver e 0 entender encontra-se na filosofia de Platão e Aristóteles. Segundo Platão, no Livro VI da República, os inteligíveis se dividem em duas classes ${ }^{10}$, aqueles que necessitam um discurso (diánoia, ou pensamento discursivo) e os que são apreendidos por via de uma visão direta, imediata, a intuição, atividade do noûs, ou nóešis. A atividade dos geômetras releva da diánoia:

E não sabes também que se servem de figuras visíveis como objetos dos seus raciocínios, mas sem pensar nelas mesmas e sim naquilo a que se parecem, discorrendo, por exemplo, acerca do quadrado em si e da sua diagonal, porém não das figuras que desenham, e da mesma forma nos demais casos; e assim as coisas que modelam ou desenham, e que têm as suas próprias sombras e imagens refletidas na água, são por sua vez empregadas por eles como imagens no afã de chegar àquelas coisas em si, que só podem ser contempladas com o olho do pensamento? ${ }^{11}$. 
Qual é, portanto, a relação entre os diagramas e o discurso? 0 alvo dos dois são as coisas em si, mas as figuras que compõem os diagramas são meras cópias e o discurso visa não às cópias, mas aos originais. 0 olhar das figuras e dos diagramas tem uma função essencial: ser a via pela qual se chega às coisas em si, o que necessita do olho do pensamento. A visão das figuras e dos diagramas não é a contemplação das ideias. A nóesis se consegue unicamente pela própria atividade do filósofo, ou seja, a dialética. Esta última atividade representa o cume do pensamento onde 0 filósofo contempla, sem o intermédio do discurso, as Ideias.

Esta oposição entre o pensamento discursivo e o pensamento intuitivo é de uma certa maneira invertida em Aristóteles. Se por Platão a dialética através do processo do discurso leva à contemplação das ideias, Aristóteles pensa que a nóesis situa-se no primeiro estágio do discurso científico, ou seja, antes da diánoia. 0 discurso científico tem por objeto demonstrações a partir de princípios ${ }^{12}$ (definições, noções comuns, e postulados). Mas os princípios não são demonstráveis. Eles requerem o noûs e a nóesisis ${ }^{13}$. A nóésis é, portanto, a contemplação direta, imediata, dos princípios que precedem e norteiam todo o discurso.

Mas é também possível introduzir a visão no discurso quando se trata de convencer ou seduzir um auditório (retórica, poética) ou perceber diretamente 0 caminho de uma demonstração (geometria). Aristóteles, na Retórica ${ }^{14}$, distinguia, entre as expressões felizes do estilo, a enérgeia que consiste literalmente em por diante dos olhos: ....̌̌

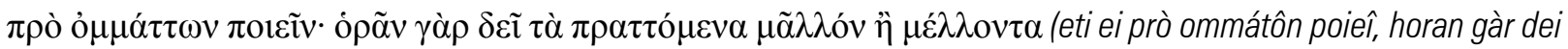
tà prattómena mâllon hē méllonta): "[A satisfação também é gerada se as palavras logram...] construir a cena diante dos olhos, pois mais vale ver 0 que é do que o que tem a perspectiva de ser"15. A parte III, 11 que segue na Retórica, é dedicado à explicitação da expressão "por diante dos olhos".

Na Poética, uma expressão equivalente (pro ommáton tithémenon) está presente:

Quando se constroem narrativas e se está envolvido na elocução em que são elaboradas, convém lembrar de dispor as cenas reais, na medida do possível, diante dos próprios olhos. Ao ver coisas de maneira sumamente vívida (energéstata), como se presentes nos fatos reais, descobrir-se-á o que é apropriado e sem que se incorra em contradições ${ }^{16}$.

Na Metafísica, Aristóteles observa que 0 ato (enérgeia), por oposição à potência (dýnamis), governa também 0 modo de tornar evidentes as propriedades geométricas nos diagramas.

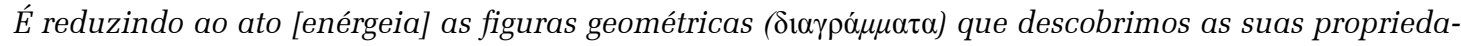

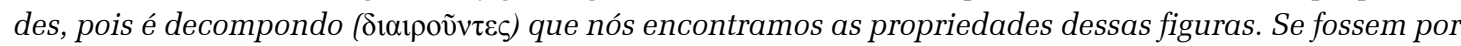

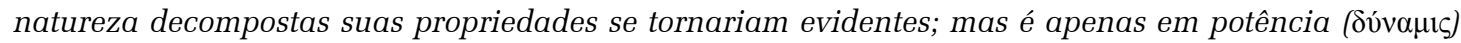
que as propriedades existem antes da decomposição. Por que a soma de três ângulos de um triângulo é igual a dois retos? Por que dois ângulos formados em torno do mesmo ponto, sobre a mesma linha, igualam-se a dois retos? Se fosse traçada a reta paralela ao lado, a demonstração tornar-se-ia imediatamente evidente. ${ }^{17}$

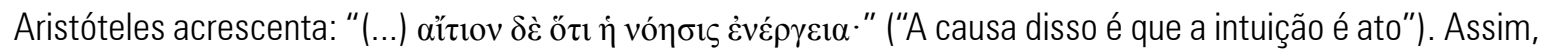
o que torna evidente a propriedade é 0 ato, pois os diagramas devem ser decompostos, para tornar evidentes as propriedades.

Em Platão e Aristóteles, o estatuto ontológico dos objetos matemáticos é certamente diferente. Platão considera que os raciocínios dos geômetras envolvem objetos ideais (por exemplo, o quadrado em si) enquanto Aristóteles afirma que os seres matemáticos são separados e imóveis, meras abstrações obtidas a partir das coisas, separadas porque abstraídas, imóveis porque os móveis dizem respeito à física e não à matemática. 0 papel dos diagramas, todavia, vem desempenhando a mesma função de representação: em Platão de realidade ideal, em Aristóteles de abstração perfeita de uma realidade física. 
As relações entre a visão e o discurso na obra de Platão e de Aristóteles nos levam, portanto à questão de entender como o papel dos diagramas nos Elementos de Euclides pode ser interpretado neste contexto. Mas antes temos que observar que o verbete diagramā não faz parte da terminologia euclidiana. Como ressalta Netz ${ }^{18}$, para designar um diagrama, Euclides utiliza katagraphe (Euclides III-33) e também o verbo katagraphein (por exemplo, II-7 e II-8).

Platão e Aristóteles utilizam o termo "diágramma" para designar as proposições matemáticas. No primeiro sentido da palavra, diagrama significa um desenho, realizado por meio de linhas (dia gramme), o que permite Netz ${ }^{19}$ observar que nos textos gregos o termo "diágramma" é uma metonímia de proposição. Essa metonímia demonstra a importância dos diagramas na geometria e nas proposições matemáticas. 0 diagrama parece assim representar 0 coração da proposição. Mas podemos também observar que na citação acima Aristóteles utiliza diagrama no sentido de construção geométrica. Utilizaremos diagrama, pois é a palavra consagrada (por exemplo, Vitrac, Saito, Netz) para designar os desenhos que acompanham as proposições nos Elementos de Euclides. A primeira questão que então se coloca é: o que é um diagrama em Euclides?

\section{Os diagramas em Euclides}

\section{como aparece o diagrama em uma proposição de Euclides?}

A primeira constatação é que um diagrama aparece ao lado de cada proposição dos Elementos de Euclides e, ao olhá-lo simplesmente, não podemos perceber a significação que ele tem para a proposição. A compreensão do diagrama está no texto da proposição. Para estudar esta primeira relação do diagrama com o texto tomaremos como exemplo a proposição I.5 dos Elementos. Para destacar as etapas da proposição utilizaremos a terminologia de Proclus. Proclus ${ }^{20}$ distingue seis momentos da proposição: a prótasis (enunciação), a ékthesis (exposição), o diorismós (a determinação), a kataskeue (construção auxiliar), a apódeixis (demonstração) e a sumpérasma (a conclusão). Não sabemos se esta terminologia já era utilizada antes de Proclus mas o que ela descreve corresponde à estrutura objetiva da proposição

em Euclides. Esta terminologia denota o que esta estrutura caracteriza e, de certo modo, constitui o estilo retórico de qualquer proposição matemática.

\section{Proposição l.5.}

[Prótasis] Os ângulos junto à base dos triângulos isósceles são iguais entre si, e, tendo sido prolongadas ainda mais as retas iguais, os ângulos sob a base serão iguais entre si.

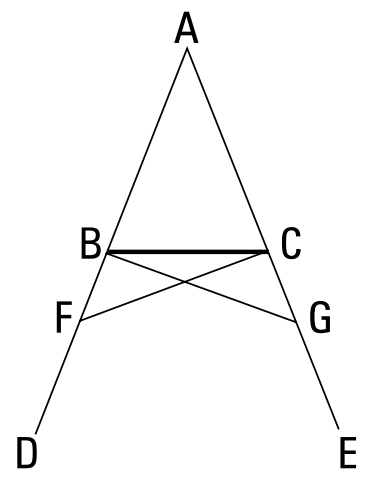

Diagrama da proposição I.5, dos Elementos de Euclides.

[Ékthesis ] Seja o triângulo isósceles $A B C$, tendo o lado $A B$ igual ao lado $A C$, e fiquem prolongadas ainda mais as retas $B D$ e $C E$ sobre uma reta com as $A B, A C$; digo que, [diorismós] por um lado, o ângulo sob $A B C$ é igual ao sob $A C B$, e por outro lado, o sob CBD ao sob BCE. 
[Kataskeuē] Toma se sobre BD o ponto $\mathrm{F}$ encontrado ao acaso, e fica subtraída da maior AE a AG igual a menor AF, e fiquem ligadas as retas $\mathrm{FC}, \mathrm{GB}^{21}$.

Isso termina a descrição do diagrama tal como aparece no texto. Podemos observar que a protasis não contém informações a respeito do diagrama, pois ela é um enunciado universal que diz respeito a todos os triângulos isósceles. Isso é um traço de todas as prótasis em Euclides. Tampouco as últimas etapas - demonstração (apódeixis) e conclusão (sumpérasma) - não acrescentam elementos ao diagrama, apesar da demonstração ser a razão de ser do diagrama como veremos adiante.

0 que diz respeito à realização do diagrama consta, portanto, na ékthesis e na kataskeuē. 0 mais relevante é que nessas etapas se descrevam atividades como "seja traçada a reta $A B$ " e, como Heath já tinha observado, que se empreguem os verbos do imperativo perfeito passivo indicando que as ações já estão realizadas, e que o desenho está feito antes de iniciar a demonstração ${ }^{22}$.

Outro aspecto ressaltado por Proclus: há dois tipos de proposições: as proposições problemas e as proposições teoremas. Um problema é essencialmente, nos Elementos de Euclides, um problema de construção (por exemplo, construir a reta que divide um ângulo em duas partes iguais). Neste tipo de proposição, a construção auxiliar representa 0 alvo apontado pela proposição, e a demonstração é uma justificativa bem fundada da construção. No caso de um teorema, que é uma proposição visando a demonstrar certa propriedade possuída por uma figura, a construção auxiliar indica o caminho da demonstração.

Em outra observação, indicada por Netz²3, o diagrama representa os pontos envolvidos no texto da proposição, primeiro, pela materialização desses por via de traçados (intersecção de linhas, segmentos), segundo, pelas letras que permitem situar os termos do texto. Netz, seguindo Charles Sanders Peirce, interpreta a letra como índice do objeto traçado (o ponto). Mas não comenta a interpretação de Peirce dos diagramas geométricos.

A escolha da teoria do signo de Peirce por Netz é adequada para a leitura dos textos matemáticos gregos. Com efeito, uma teoria da língua como a de Saussure ou a de Jacobson não poderia, com a sua estrutura dicotômica (significante-significado, eixo paradigmático-eixo sintagmático), dar conta de todas as dimensões semióticas ambos de um texto escrito e do diagrama que acompanha este texto em Euclides, o que queremos mostrar a seguir.

Com efeito, nos seus escritos, Peirce ressalta:

O terceiro caso é onde a relação dual entre o signo e o objeto é degenerada numa mera semelhança entre eles. Chamo um ícone um signo que fica no lugar de algo simplesmente por parecer-se com ele. Ícones substituem tão bem os seus objetos que fica muito difícil distingui-los deles. Assim são os diagramas da geometria. Com efeito, um diagrama, enquanto tem uma significação geral, não é um ícone puro. Mas no meio dos nossos raciocínios nos esquecemos esta abstração em grande medida, e o diagrama é para nós a coisa mesma ${ }^{24}$.

Assim, se as letras são índices, o diagrama mesmo enquanto desenho traçado é ícone, por semelhança com os objetos geométricos. Mas a significação geral do diagrama faz com que ele não seja um puro ícone.

0 diagrama com letras tem assim três aspectos: as letras enquanto índices, os traçados enquanto ícones e a significação geral que não se reduz a estes componentes. Isso leva, portanto, à primeira questão: será que o ponto é efetivamente traçado ou o que vemos no diagrama é apenas um signo que representam um ponto? Pois o que compõe um diagrama não são os objetos da geometria, isto é, as figuras (schēmata). Segundo a definição 13 de Euclides, "Uma figura é o que é contido por alguma ou algumas fronteiras"25. Os objetos são definidos pelos limites: um segmento pelos pontos (def. 3), um círculo pela circunferência, um quadrilátero pelos quatro lados etc. Mas esses limites são apenas representados. Com efeito "um ponto é aquilo de que nada é parte", enuncia a primeira definição dos Elementos. Nos diagramas, os pontos são representados por traços materiais, isto é, com certa espessura. Na realidade os objetos considerados, pontos, segmentos, círculos estão ausentes dos diagramas mas são duplamente representados pelos traços e pelas letras. 
Neste aspecto, Euclides pode ser entendido do modo de Platão ou do modo de Aristóteles, pois o objeto matemático pode ser uma ideia existente independentemente do intelecto (noûs) ou produto do intelecto através do processo de separação da matéria (o geômetra raciocina sobre o círculo de bronze enquanto círculo). Os objetos da matemática são em todos os casos objetos ideais. Isto implica que os diagramas não são mais os objetos mesmos, mas uma representação que demanda uma interpretação, uma leitura. 0 diagrama é uma parte do texto e do discurso.

Os trabalhos de Ken Saito que realizam um estudo sistemático dos manuscritos, aliás, tentam preencher a lacuna de Heiberg e outros editores posteriores de Euclides que trataram apenas do texto dos manuscritos sem prestar atenção e submeter a uma análise precisa os diagramas que acompanhavam os textos.

Uma observação de Ken Saito a respeito da edição dos diagramas de Euclides nos manuscritos árabes vem confirmar que o diagrama é um texto: "além disso, em todos os manuscritos árabes e aqueles latinos traduzidos do árabe, a figura é inversa na direção horizontal e, como consequência, os pontos DABE se ordenam da direita à esquerda" ${ }^{26}$.

Veja abaixo a versão do manuscrito grego e a do manuscrito árabe.

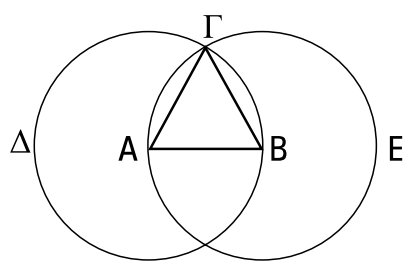

Codex P

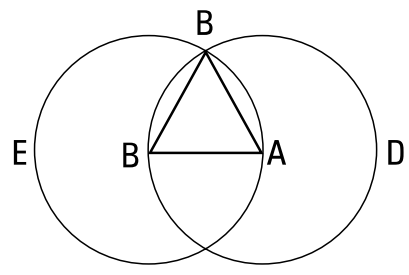

Codex G B

Diagramas da proposição I-1. 0 Codex P é um manuscrito grego. 0 Codex GB, uma tradução latina de um manuscrito árabe.

A ordem da leitura dos dois diagramas apresenta uma simetria axial.

As letras estão para ser lidas, portanto, enquanto texto respeitando a ordem de leitura da língua (que não é a mesma para o grego e para o árabe) e, assim, as letras restituem ao diagrama certa temporalidade. Há uma oposição dentro do diagrama entre a visão global e imediata, e as letras que indicam as etapas de construção do diagrama. Há certa ordem de leitura do diagrama.

0 fato de utilizar letras em um diagrama parece ter sido uma aquisição recente no tempo de Euclides. Platão, por exemplo, não utiliza letras no Menon para designar linhas e quadrados que estão diante dos olhos dos protagonistas do diálogo. Aristóteles utiliza às vezes raciocínio envolvendo letras. Os diagramas são ausentes dos manuscritos do estagirita, mesmo se podemos pensar que estavam traçados durante as palestras do Mestre, e os manuscritos designam os objetos de um modo um pouco diferente do de Euclides: utilizam apenas uma letra para denotar um lado ou duas letras para um ângulo, como, por exemplo, Aristóteles, nos Analíticos anteriores ${ }^{27}$. Aliás, Aristóteles emprega letras também para denotar os termos da proposição lógica, explicando que ele imita, nesta prática, os geômetras ${ }^{28}$. Já Autólico de Pitane (f. 360-290) utilizava as letras do mesmo modo do que Euclides, como por exemplo, em A Esfera em Movimento ${ }^{29}$. A normalização da notação parece ter se iniciado na época mesma de Aristóteles ou um pouco depois.

Mas isso o leva à segunda questão colocada pela observação de Peirce: por que nos diagramas convivem índices e ícones e qual é o modo de convivência? Se o diagrama enquanto traçado remete aos objetos por semelhança, as letras ligam o diagrama ao texto discursivo da proposição. Apenas as letras aparecem na ékthesis e na kataskeue. A dichotomia do diagrama remete a dichotomia na proposição entre 0 diagrama e 0 texto.

Uma correspondência se estabelece, portanto, entre qualquer elemento do diagrama e o enunciado da ékthesis e da kataskeue. Para retomar nosso exemplo da proposição I.5. "Seja o triângulo isósceles $A B C$, tendo o lado $A B$ igual ao lado $A C$ ", o que corresponde a um triângulo $A B C$ traçado no diagrama. 0 fato $A B=A D$ apesar de ser sempre 
aproximativo na figura é guardado na memória, registrando uma ideia ligada ao triângulo $A B C$. Assim, o traçado tem valor de ideograma ${ }^{30}$ (não é mero índice nem símbolo, mas uma unidade de significado, conceito escrito de uma verdadeira língua), pois é uma representação de todo enunciado por um signo completamente independente da matéria do texto. Assim, o texto grego das proposições se duplica com o diagrama de uma série de traços contendo todos significados indicados pelo texto. Qual é a vantagem do diagrama se é apenas uma repetição do texto sob forma de ideogramas? A vantagem é que decifrar o diagrama, uma vez bem conhecidas as regras de construção, permite acessar o sentido imediatamente pela visão dos elementos do diagrama, sem apelar de novo ao texto discursivo. A função do diagrama reside, portanto, na substituição dos monemas do texto discursivo pelos morfemas que representam os ideogramas que constituem o diagrama. A diferença essencial entre os ideogramas do diagrama e ideogramas de uma língua escrita consiste, portanto, em que os significados de um diagrama atuam unicamente dentro de uma proposição. Outro diagrama e outra proposição levam a outros significados denotados pelos elementos do diagrama.

0 diagrama concentra em si todas as significações que the confere o texto e releva, uma vez realizado, a contemplação imediata de ideias, a nóesis. 0 diagrama permite assim entregar à visão de uma só vez de todos os elementos essenciais da proposição. 0 texto, a dianoia, tem sempre a dimensão temporal. 0 texto é, no entanto, a última instância na medida em que este entrega a significação do diagrama e, aliás, opera sobre esse no decorrer da demonstração.

Se a exposição (echtesis) apresenta os dados do problema - as premissas (hypothesis) diria Aristóteles - a construção auxiliar (kataskeuè) acrescenta os termos necessários ao desempenho da demonstração. Como vimos na introdução, segundo Aristóteles, há construções que tornam evidente a propriedade. Em geral, a kataskeuè não esgota a necessidade da demonstração, ou seja, ela é mais o substrato da demonstração do que visão imediata, mas também indica o caminho (hodós), o método (metá hodós).

Descartes, nas Regulae, criticava os gregos por não ter deixado nas suas obras traços da análise deles, o que sua obra La Géometrie procurará restituir ${ }^{31}$. A kataskeue é talvez a última relíquia que permaneça da análise.

\section{O diagrama e a demonstração}

0 aspecto de ideograma que reveste 0 diagrama se manifesta, sobretudo na parte da demonstração (apódeixis) de uma proposição. Para mostrá-lo consideramos a demonstração da proposição I.5:

[Apódeixis] Como de fato, por um lado, a $A F$ é igual à $A G$, e por outro lado, a $A B$ à $A C$, então as duas, $F A, A C$, são iguais às duas $G A, A B$, cada uma a cada uma; e contêm o ângulo sob FAG comum; portanto a base FC é igual à base GB, e o triângulo AFC será igual ao triângulo AGB, e os ângulos restantes serão iguais aos ângulos restantes, cada um a cada um, sob os quais se estendem os lados iguais, por um lado, o sob $A C F$ ao sob $A B G$, e, por outro lado, o sob $A F C$ ao sob $A G B$. E, como a AF toda é igual à $A G$ toda, das quais a $A B$ é igual à $A C$, portanto, o restante $B F$ é igual ao restante $C G$. Mas também a $F C$ foi provada igual à $G B$; portanto as duas $B F$, FC são iguais às duas $C G$, GB, cada uma a cada uma; também o ângulo sob BFC é igual ao ângulo CGB, e a base BC deles é comum; portanto, também o triângulo BFC será igual ao triângulo CGB; e os ângulos restantes serão iguais aos ângulos restantes, cada um a cada um, sob os quais se estendem os lados iguais; portanto por um lado o sob FBC é igual ao sob GCB, e por outro lado, o sob BCF ao CBG. Como, de fato, o ângulo sob $A B G$ todo foi provado igual ao ângulo sob ACF todo, dos quais o sob $C B G$ é igual ao sob $B C F$, portanto o sob $A B C$ restante é igual ao sob ACB restante; e estão junto à base ABC. Mas foi provado também o sob FBC igual ao sob GCB; e estão sob a base.

[Sumperesma] Portanto, os ângulos junto à base dos triângulos isósceles são iguais entre si, e, tendo sido prolongadas ainda mais as retas iguais, os ângulos sob a base serão iguais entre si; o que era preciso provar $^{32}$. 


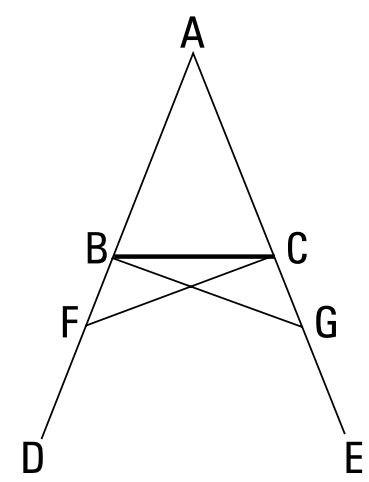

Diagrama da proposição 1.5 dos Elementos de Euclides.

Lembremos que a ékthesis e a kataskeuē forneciam apenas o traçado das principais unidades do diagrama: o triângulo $\mathrm{ABC}$, os prolongamentos $\mathrm{BD}$ e CE e a determinação dos pontos $\mathrm{F}$ e $\mathrm{G}$.

A primeira observação trivial ao ler a apodeixis é que não podemos seguir este texto sem olhar simultaneamente, a cada trecho, o diagrama, a fim de entender o significado dos termos envolvidos. A segunda preocupação do leitor é distinguir as etapas do problema. Ora, trata-se primeiro, na proposição I. 5, de demonstrar que os triângulos AFC e ABG são iguais. A leitura do diagrama não consiste mais (como na leitura do traçado) em ler os elementos do diagrama, mas certas figuras do diagrama: por exemplo, comparar os triângulos AFC e ABC. Tendo em vista estas figuras, analisam-se os atributos desses triângulos. Mas o que é ter em vista?

Vemos que as letras são índices, e figuras e diagramas, ícones. Assim aos índices A, F, C corresponde o ícone triângulo AFC traçado. Mas o triângulo traçado no seu sentido mais geral (diz Peirce) não é um puro ícone. Por um lado, o leitor na demonstração o confunde com o objeto ideal; por outro, o ícone incorpora as propriedades que 0 texto lhe confere por via dos índices (comparam-se os lados de dois triângulos, um ângulo a um outro). No seu sentido mais geral, o ícone se torna um ideograma, concentrando todas as significações que a demonstração justificou.

0 diagrama é invocado a cada momento e a demonstração só pode ser seguida através dos elementos do diagrama. Há um vai e vem entre os enunciados do texto e os elementos da figura, ou seja, o diagrama se enche dos sentidos que a demonstração vem lhe entregando. Estes elementos concentram o sentido. Com a ekthesis e a kataskeué tínhamos uma primeira leitura do diagrama. A demonstração é uma segunda leitura mais rica na medida em que mobiliza não apenas os dados da proposição, mas também invoca outras proposições: 0 caso de igualdade dos triângulos da proposição I. 4, mas também da proposição I. 3, para pôr sobre a reta AE um segmento igual a AF.

A segunda etapa da demonstração é a comparação dos triângulos BCF e CBG para demonstrar a sua igualdade e assim concluir utilizando diferenças de ângulos. Assim o diagrama sofre outro recorte, mas sem apagar o primeiro, pois os triângulos BCF e CBG são partes dos primeiros triângulos AFC e AGB. Assim dois outros ícones no diagrama se tornam ideogramas. Finalmente, são as considerações juntas sobre esses quatro triângulos que levam à conclusão.

Ao mesmo tempo em que se enunciam no texto as deduções, o texto deixa o lugar ao diagrama onde interagem os ícones.

Os elementos dos diagramas não têm, portanto, apenas valor de ideograma nas etapas da echtesis e da kataskeué. A demonstração leva uma onda de significações novas e os ideogramas interagem com o texto. Conhecido o texto da proposição e o diagrama, o texto escrito pode sumir, pois fica concentrado no diagrama. "É reduzindo ao ato [energeia]

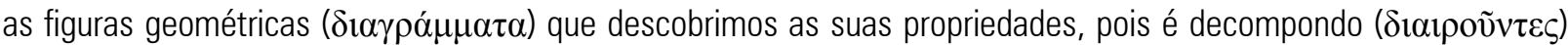
que nós encontramos as propriedades dessas figuras", diz Aristóteles. A decomposição do diagrama pelo texto da proposição entrega o significado em ato do que este continha em potência. Assim pode 0 diagrama se fundir com 0 texto. Essa fusão implica que o diagrama é o texto inteiro e como qualquer texto tem uma gramática e um estilo. 


\section{O que valida a demonstração?}

Permanece a questão de saber o que valida uma demonstração. Com efeito, a demonstração não opera a partir da prótasis, que é uma proposição universal, mas a partir da ékthesis. Ora, a ékthesis descreve certo diagrama que parece ser um objeto particular. Como então demonstrar uma proposição universal a partir de um objeto particular? Este problema era já discutido na antiguidade.

Se a ékthesis enuncia, por exemplo, que um triângulo $A B C$ seja traçado, o que assegura que o raciocínio desempenhado a respeito deste triângulo vale também para qualquer triângulo? 0 triângulo traçado não é 0 objeto da demonstração, mas sim o que representa o objeto da demonstração. Aristóteles já havia ressaltado este ponto nos Analíticos Anteriores:

Não é de se supor que qualquer absurdo resulte da exposição dos termos. Não baseamos nosso argumento na realidade de um exemplo particular; estamos fazendo o mesmo que o geômetra que diz que esta linha do comprimento de um pé, ou linha reta ou linha sem largura existe quando não existe, ainda que não se sirvam de suas ilustrações no sentido de deduzir alguma coisa delas.... Nós empregamos a exposição (ektithestai) como alguém emprega a percepção sensorial. Nós não as empregamos como se a demonstração fosse impossível sem essas illustrações, como seria na falta das premissas de um silogismo. ${ }^{33}$

Proclus, no seu comentário, responde à questão utilizando argumentos similares, ressaltando que os "geometras utilizam os objetos construídos do diagrama não como figuras particulares, mas como figuras semelhantes a todas as outras da mesma espécie" ${ }^{\prime 3}$.

A percepção sensorial se separa do rigor do texto dedutivo. Este aspecto ficou alias como a vulgata da prática geométrica até hoje, pois, como o ressalta Poincaré, a "geometria é a arte de raciocinar corretamente em cima de diagramas falsos" ${ }^{\prime 35}$. Com a ressalva que se um diagrama não respeita as propriedades métricas e projetivas, ela respeita as propriedades topológicas. Assim um círculo pode ser representado por uma curva aproximativa, mas é preciso que esta curva esteja fechada.

Resta também que a demonstração deve evitar certos erros que enuncia Aristóteles nos Analíticos Posteriores $(I, 5): 1)$ f fato de pensar que demonstramos uma proposição universal enquanto providenciamos apenas a demonstração de um caso específico; 2) 0 erro que consiste em demonstrar analisando casos específicos em vez de fazer uma única demonstração que vale por todos os casos; 3) Enfim demonstrar uma proposição que enuncia certas propriedades de um triângulo escaleno enquanto a demonstração considera apenas um triângulo equilátero. Em Euclides, a rede lógica da demonstração permanece no texto e a verificação do bom uso das regras lógicas não pertence ao diagrama. Mas há um elemento essencial, a nosso ver, que falta na escrita: o papel do matemático, em carne e osso, que a restitua aos ouvintes.

0 enunciado da proposição, o comentário da figura e o desempenho da demonstração envolvem a atividade e o talento do matemático que torna vivo o discurso e, com gesto, mímica, ênfase, movimento de surpresa afetada, paixão ou prazer que atravessa o olhar, dá conta de cada etapa, facilitando assim a assimilação da demonstração. Por exemplo, toda a demonstração da proposição 5 acima descrita se anima dos gestos comentando a construção da figura, indicando os triângulos a serem comparados, insistindo sobre os trechos mais difíceis, reagindo às objeções do auditório, tal como um duelo oratório.

Assim a relação entre diagrama e texto anima-se, e o diagrama não é mais considerado como um diagrama particular, mas como qualquer diagrama podendo responder às propriedades enunciadas no traçado descrito na ékthesis e na kataskeue. 0 diagrama é mais do que o ícone na medida em que representa todos os diagramas do mesmo tipo. Com o orador, o diagrama incorpora a generalidade envolvida nas hipóteses da proposição. 0 diagrama se torna 0 texto falado. Este aspecto reforça nossa ideia que um diagrama é composto de ideogramas já que as figuras do diagrama são uma representação simbólica das propriedades enunciadas no texto que a fala do matemático articula. 


\section{A língua dos diagramas}

\section{A fabricação do diagrama: regras sintáticas e ideogramas}

0 processo de construção dos diagramas segue as regras estritas ditadas pelos postulados e as três primeiras proposições de Euclides. Os postulados indicam 1) a possibilidade de traçar uma reta de um ponto a um outro ${ }^{36}, 2$ ) de prolongar continuamente uma reta ${ }^{37}$, 3) traçar um círculo a partir de um ponto tomado por centro e de um intervalo ligando 0 centro a um outro ponto ${ }^{38}$. Os dois outros postulados afirmam também propriedades ligadas às construções: 4) que "os ângulos retos são todos iguais entre si" assegura que uma vez construídas perpendiculares às retas distintas, os ângulos descritos serão iguais. 0 quinto postulado enuncia uma condição de encontro de duas retas e logo a possiblidade de considerar o ponto de encontro, ou ainda a condição de possibilidade de construir um triângulo. As três primeiras proposições são também essenciais aos diagramas, construir um triângulo equilátero, traçar a partir de um ponto um segmento igual a uma reta dada, construir o segmento diferença entre dois segmentos dados. Estas três proposições aparecem utilizadas em várias proposições dos Elementos, por exemplo, em seis proposições do livro I 5 proposições do livro III" ${ }^{39}$.

As construções (Problemas) são necessárias à formulação mesma dos teoremas. Por exemplo, a proposição 47 (que Proclus atribuía a Pitágoras, do que vem a sua denominação consagrada: 0 teorema de Pitágoras) não teria significação não fosse a proposição precedente I. 46 ("Descrever um quadrado sobre a reta dada"). Com efeito, a proposição I.47 ("Nos triângulos retângulos, o quadrado sobre o lado que se estende sob o ângulo reto é igual aos quadrados sob os lados que contêm o ângulo reto") precisa dos quadrados efetivamente construídos, ou seja, que a possibilidade da construção esteja previamente estabelecida. Assim o diagrama da proposição I.46 constitui um dos elementos essenciais do diagrama da protásis I.47, a proposição em ato diria Aristóteles.

Assim, os elementos do diagrama são, além dos determinados pelos postulados, aqueles que são os resultados das proposições problemas. Estas construções conferem aos diagramas certo registro de significações invariáveis mesmo se 0 critério fica em última instância no texto das proposições. Voltaremos a discutir este ponto mais adiante.

\section{Diagramas conformes ou não conformes?}

Os trabalhos de Reviel Netz ${ }^{40}$ e de Ken Saito ${ }^{41}$ colocaram uma questão nova no que diz respeito ao papel dos diagramas na matemática grega em geral e especialmente nos Elementos de Euclides. Reviel Netz e Ken Saito apontaram a necessidade de submeter os diagramas, assim como Heiberg fez com 0 texto ${ }^{42}$, à leitura crítica. Entre 0 texto e o diagrama aparecem às vezes discrepâncias de conteúdo. A informação contida no texto não é conforme ao que 0 diagrama apresenta, ou em outras ocasiões, o diagrama contém informações que não constam no texto. Antes de dar exemplos destes fenômenos que apontam Netz e Saito, devemos observar que a kataskeué (construção auxiliar) nem sempre está presente numa proposição. Trata-se de uma construção suplementar, isso é que não consta na exposição, mas que é necessária para a implementação da demonstração. Outro aspecto é que, como o ressalta Proclus, há dois tipos de proposições: as proposições problemas e as proposições teoremas. Um problema é essencialmente, nos Elementos de Euclides, um problema de construção (por exemplo, construir a reta que divide um ângulo em duas partes iguais). Neste tipo de proposição, a construção auxiliar representa o alvo apontado pela proposição, e a demonstração é uma justificativa bem fundada da construção. No caso de um teorema que é uma proposição visando a demonstrar certa propriedade possuída por um objeto, a construção auxiliar indica o caminho da demonstração.

0 diagrama, que é traçado antes da ékthesis e da kataskeuē, contém às vezes mais informação do que o texto ${ }^{43}$. Assim distingue Netz nos diagramas do livro XIII de Euclides três tipos de letras: letras completamente especificadas, as subespecificadas e as letras completamente subespecificadas. Completamente especificado é, por exemplo, o ponto A designado na exposição como centro do círculo. 0 círculo de raio $A B$ já não menciona se $A$ é 0 centro ou não do círculo, e, portanto, é uma letra subespecificada. Enfim considera-se um círculo de centro $C$ de raio $C B$ e, acrescenta-se DB é 
igual a duas vezes $\mathrm{CD}$. A letra $\mathrm{D}$ é completamente subespecificada em relação ao texto, que não acrescenta que $\mathrm{D}$ é o ponto diametralmente oposto ao ponto B, pois esta informação lê-se apenas no diagrama. No livro XIII apenas 47\% das letras são completamente especificadas. 0 diagrama contém, portanto, mais informação do que 0 texto. Netz estabelece assim a necessidade do diagrama para a compreensão do texto e a provável existência dos diagramas desde as primeiras edições dos Elementos.

Outro aspecto importante dos diagramas nos manuscritos é analisado por Ken Saito ${ }^{44}$. Os diagramas são muitas vezes "hiperespecificados", isto é, contém objetos com propriedades que prejudicam a generalidade considerada na proposição. Por exemplo, o diagrama da proposição I.4 representa em vários manuscritos triângulos equiláteros, 0 diagrama da proposição I. 26 (caso ALA de igualdade de triângulos) figura em um manuscrito com triângulos equiláteros, e em outro com triângulos retângulos, enfim o diagrama da proposição I.47 (o chamado teorema de Pitágoras), representa um triângulo retângulo isósceles. Saito ressalta que as demonstrações não são afetadas por esta hiperespecificação e observa que "uma tendência dos manuscritos é que eles tendem à simetria criando entre outros mais triângulos e trapézios isósceles" ${ }^{45}$. A simetria diz apenas respeito a considerações estéticas e não matemáticas. Como se o copista estivesse mais preocupado com a beleza da figura do que com o fato de estar conforme as propriedades estipuladas no texto. Outra razão da hiperespecificação dos diagramas seria que é de fato mais fácil construir um triângulo equilateral, isósceles ou retângulos do que um triângulo escaleno. Assim o valor estético do diagrama parece superar o seu valor matemático. 0 diagrama aparece assim estilizado nos manuscritos. Esta consideração leva a investigar o estilo do texto e dos diagramas.

\section{O estilo do texto e o estilo dos diagramas}

0 caráter formular de certos elementos em Euclides já tinha sido apontado por Heath. Assim ele explica o processo abreviativo que sofre a designação de um ângulo:

o ângulo BAC. A expressão grega completa seria hē hypo tôn $B A, A C$ periochoménè gonía, o ângulo contido pelas (linhas retas) BA, AC. Mas era uma prática comum entre os matemáticos gregos, por exemplo, Arquimedes e Apolônio (mas não em Euclides), utilizar a expressão ai BAC para ai (linhas retas) BA, AC. Então o verbo periochoméne sendo suprimido, a expressão torná-se-ia primeiro hē hypo tôn BAC gonía, depois he hypo BAC gonía e, finalmente hē hypo tôn BAC sem gonía assim como encontramos regularmente em Euclides. ${ }^{46}$

Do mesmo modo, os outros objetos são designados pelas letras que aparecem no diagrama. Em vez de "o ponto Z", Euclides escreve "tó Z". 0 artigo neutro basta para identificar o ponto, pois o verbete semeiôn é neutro. A reta AB é designada por hé $A B$, etc.

Na introdução do seu Dictionnaire historique de la terminologie des grecs, Charles Mūgler ressalta:

Esta língua sóbria e elegante, com o seu vocabulário ao mesmo tempo preciso e diferenciado, invariável exceto por algumas pequenas mudanças semânticas, através de mil anos da história do pensamento grego, com sua sintaxe nuançada e restrita, com o seu aparelho formular repetido de texto em texto e ritmando a dicção geométrica como as fórmulas homéricas ritmam a epopéia, apresenta-se desde a sua primeira aparição, em Euclides, como um meio de expressão tão adequado às representações e aos conceitos que ela tinha de dar conta, que ela parecia ter saído toda armada da cabeça de Zeus, segundo o dito célebre de P. Tannery aplicado à geometria grega. ${ }^{47}$

Mugler ilustra esta caracterização do discurso euclidiano pelo processo abreviativo sofrido pelos termos designando os objetos matemáticos, pela descrição das diversas funções lógicas das preposições e das conjunções, e pelas 
expressões concisas que expressam as relações (igualdades de razões, proporcionalidades, contato da tangente com uma curva etc). Com seu dicionário, Mugler elabora a lista de muitas expressões formulares que atravessam o discurso da matemática grega e demonstra a permanência deste tipo de discurso.

Germaine Aujac, comparando os tratados de Autólico de Pitane, de Euclides e de Teodósio de Bitínia, havia ressaltado uma permanência notável na expressão dos teoremas ${ }^{48}$. G. Aujac analisa este fenômeno como 0 fato que nesta época o vocabulário e o estilo matemático já haviam sido fixados em um tipo de "linguagem formular", retomando assim as teses já defendidas por Mugler. Aujac observa a semelhança entre as fórmulas da matemática e as da epopeia, explicando isso pelo fato que a transmissão do saber era oral, e a matemática necessitava de fórmulas que pudessem facilmente se fixar na memória.

A linguagem dos teoremas se distingue da prosa literária (e também da poesia) no fato que cada termo da frase é ao mesmo tempo necessário e suficiente. É este caráter irredutível do enunciado que assegura aos teoremas da geometria a memorização e a perenidade ${ }^{49}$.

Ressalta também na introdução à sua tradução de Autólicos que a estrutura da proposição em Autólicos é já dividida em seis partes assim como a mesma de Euclides, utilizando as mesmas palavras para introduzir cada parte (prótasis, ékthesis etc. $)^{50}$.

0 estudo sistemático de Reviel Netz analisou o caráter formular do texto e do estilo de Euclides e dos matemáticos deste período. Observa primeiro que o texto possui um vocabulário pequeno (cerca de duzentas palavras para 95\% do corpus da matemática grega) ${ }^{51}$. 0 texto é, principalmente, constituído de fórmulas (aproximadamente duzentas também) que dão conta dos objetos geométricos envolvidos (pontos, retas, círculos etc.), da estratégia de demonstração (do mesmo modo, provar-se-ia, assim a propriedade, digo que, como devia ser demonstrado etc.), das conexões da argumentação (como... assim etc.), das relações entre objetos (encontro de duas retas, um ponto sobre uma reta etc.). Assim um texto de uma proposição pode ser decomposto em uma sequência de fórmulas que pode ser representada esquematicamente por uma árvore lógica.

Carlos Gonçalves estudou particularmente este aspecto procurando descrever as estruturas sintáticas que materializam esta sequência e chama estas formações sintáticas de estruturas matriciais ${ }^{52}$, especificando assim uma expressão já utilizadas por Netz que ele, aliás, cita:

Em um nível ainda mais alto, é possível ver a proposição toda como uma tal matriz (...). Há expressões validando um argumento. Sua essência é que elas combinam afirmações em uma matriz fixa na qual se sabe que o resultado deriva das premissas. (...) quando um grego prova um resultado geral, o que ele faz é validar uma matriz, em que objetos particulares podem, a partir daquele momento, ser encaixados. ${ }^{53}$

Gonçalves chega a uma classificação de tais matrizes no que diz respeito aos enunciados (prótasis) dos teoremas em alguns livros dos Elementos de Euclides ${ }^{54}$. Mas estas se encontram também nas outras partes da proposição. $\mathrm{Na}$ ékthesis, kataskeuē e apódeixis, estas desempenham o intermediário entre o texto e os elementos do diagrama, por exemplo, entre reta $A B$ enunciada no texto e o traçado da reta $A B$ marcado pelas letras $A$ e $B$, "o sob BAC" do texto é 0 ângulo traçado entre as retas $A B$ e $A C$, denotado pelo traçado efetivo e as letras, assim como relações entre triângulos. As estruturas matriciais permitem incorporar dentro do diagrama todos os significados do texto.

Este fenômeno pode esclarecer a origem e a gênese do caráter formular dos textos matemáticos. Com efeito, 0 que leva à uma formulação abreviada dos objetos é o vai e vem entre o texto e o diagrama. À medida que o diagrama integra as significações do texto, o diagrama influi sobre a enunciação destas significações, já que o texto se apoia sobre 0 diagrama. Não é então de se estranhar que a denominação de ângulos seguisse o processo descrito por Heath. Ver o ângulo delimitado pelas retas $A B$ e $A C$ levou à expressão hē hypo tôn BAC. Temos que imaginar como um matemático que estuda uma proposição frente a ouvintes, falando do ângulo, juntaria o gesto à palavra, desenhando 
no ar as semi-retas que delimitam o ângulo. A relação entre 0 texto e o diagrama se duplica na relação entre a fala e o gestual do matemático. Não devemos esquecer que o escrito é apenas em geral o relato estenográfico da atividade viva do matemático frente a um público.

0 texto das proposições possui, portanto, um estilo retórico. A estrutura em seis partes da proposição (enunciação, exposição, construção auxiliar, determinação, demonstração e conclusão) responde de certo modo às quatro partes do discurso definidas por Aristóteles na Retórica III-13: prólogo, exposição, demonstração e epílogo. Os dois tipos de discursos visam a convencer. Mas além da estrutura, há certos aspectos da proposição que lembram os procedimentos retóricos.

Um dos aspectos de uma proposição em Euclides é a repetição. 0 conteúdo mesmo da proposição é repetido quatro vezes através dos seis momentos da proposição ${ }^{55}$. A enunciação geral é seguida da exposição e da determinação (esta sempre introduzida por "digo que' ou "é preciso"), que repetem a enunciação. No final da demonstração ainda 0 conteúdo da determinação é repetido. Enfim, a conclusão repete a enunciação da proposição. Esta estrutura parece um canto ritmado pelo refrão.

A exposição (ékthesis) e a construção auxiliar (kataskeuē) lembram também uma figura retórica que Aristóteles caracteriza como "por diante dos olhos", que Cícero irá denominar como evidência, e Quintiliano como hipotipose. Segundo Quintiliano, a hipotipose é uma figura retórica de pensamento.

Quanto à figura que, como diz Cícero, coloca os próprios objetos diante de nossos olhos, emprega-se não para indicar que um fato aconteceu, mas para fazer ver como aconteceu... outros chamam a hipotipose (hypotyposis), isto é, uma representação tão viva dos objetos pela palavra que se acredita mais ver do que ouvir a narrativa ${ }^{56}$.

É exatamente a função da exposição e da construção auxiliar: descrever o traçado do diagrama a fim de por diante dos olhos o objeto da proposição. Deste ponto de vista, o diagrama e o texto que lhe corresponde é a hipotipose da proposição.

Outra relação pode ser estabelecida entre o estilo de Euclides e a retórica, o papel desempenhado pela memória. Cícero no De oratore, Livro II, LXXXVII, atribui ao pre-socrático Simonide a invenção da memória artificial, técnica destinada a ajudar a memorização do discurso pelo orador.

[...] Ele deduziu que nos seria mais fácil de conservar a lembrança das ideias que a audição nos transmite, ou que a imaginação concebe, se o socorro da visão fosse tornar a impressão mais viva; que então os objetos invisíveis, inapreensíveis pelos nossos olhos iam parecendo tomando um corpo, uma forma, uma figura, e que o que o nosso pensamento não poderia abraçar, a vista nos faria perceber. Estas formas, esses corpos, assim como todos os objetos que caem diante dos nossos olhos, advertem a memória, e a mantêm desperta. Mas estes precisam de lugares, pois não se pode formar a ideia de um corpo sem que se junte a do espaço que ele ocupa..$^{57}$

Na prática do geômetra o diagrama permite memorizar as etapas do discurso contido na proposição. É talvez, na história da matemática como na história do saber grego, o exemplo mais espetacular da aplicação deste método de memória artificial. Isso reforça nossa ideia de que o diagrama é um conjunto de ideogramas na medida em que é recipiente de todos os significados e de todas as etapas lógicas da proposição. Depois de ter lido e analisado a demonstração, com uma leitura acompanhada pela contemplação do diagrama, o diagrama não é mais metonímia da demonstração, como Netz interpreta o significado do termo diágramma em Aristóteles, mas sim o todo, a proposição inteira condensada em traços e letras. Memorizar o diagrama é memorizar a proposição toda.

Essas observações mostram o quanto é interessante relacionar a prática retórica e a matemática grega como aliás o mostrou Alain Bernard no estudo do caso de Pappus ${ }^{58}$. 
Há, todavia, uma grande diferença entre a retórica e o estilo da proposição de Euclides: a falta de recurso à emoção. Aristóteles observa que

[...] a questão do estilo ocupa um espaço necessário em todo ensino; não é destituída de importância quando se trata de expor um assunto com clareza, exprimir-se de uma maneira ou de outra. Todavia, não se deve exagerar a importância do estilo. Todas essas artes são imaginativas e visam seduzir o auditório.

Para ensinar geometria, ninguém recorre a esses procedimentos. ${ }^{59}$

0 estilo da proposição em Euclides é de fato minimalista usando, como vimos, um vocabulário pobre, expressões abreviadas e invariáveis, recorrendo a repetições visando unicamente à eficácia do raciocínio, ao caminho mais curto que leva à conclusão. Mas este estilo austero não tira da geometria o seu valor estético. Como o ressalta Aristóteles na Metafísica, "o belo é pelo contrário o objeto principal do raciocínio dessas ciências [as ciências matemáticas] e de suas demonstrações... As formas mais alta do belo são a ordem, a simetria, o definido, e isto é, sobretudo o que fazem aparecer as ciências matemáticas." ${ }^{60}$

\section{Conclusão}

0 estatuto do diagrama na proposição de Euclides é, portanto, crucial em vários sentidos. Acompanha primeiro os passos do texto que descreve os dados da proposição e permite apontar assim o diorismo, ou seja, o que está para ser demonstrado. 0 diagrama permite o desempenho da demonstração que opera recorrendo a elementos que constam no diagrama, ou que a ékthesis e a kataskeuē acrescentam (por exemplo, igualdade de segmentos). Enfim, o diagrama permite integrar na memória todas as etapas da demonstração que a contemplação da figura pode fazer ressurgir. Podemos assim entender melhor por que os gregos chamavam theoremata as proposições, pois teorema tem a mesma raiz do que theorein, que significa contemplar.

0 diagrama é também sem dúvida um fator do processo que levou ao caráter formular do discurso matemático já que o diagrama interfere intimamente nos enunciados das diferentes fases das proposições geométricas.

Tentamos mostrar como os diagramas geométricos são fonte de reflexão filosófica dos pensadores da antiguidade grega. A relação entre diagrama e texto insere-se assim num contexto onde o diagrama geométrico se reveste de significações estilísticas, retóricas, e permite a filosófos como Aristóteles precisar como a lógica, a retórica, as poéticas enriquecem a ligação entre 0 ver e 0 entender. Não é por acaso que o verbete figura (schema) se emprega também nas expressões figura retórica, figuras do silogismo, figuras da poética, e que este termo desempenhará um papel essencial no caminho da estética ao entendimento na filosofia de Kant.

Mas o diagrama não permanece uma mera ilustração da proposição. Incorporado as informações do texto, construção e demonstração, o diagrama torna-se o reflexo da proposição toda e toma o lugar dela. 0 diagrama não é apenas metonímia da proposição, ele é a proposição.

A matemática sofreu desde os gregos até hoje múltiplas transformações, mas como ressaltou J. Dieudonné "acho que explodindo além das suas estreitas fronteiras tradicionais, ela [a geometria] revelou os seus poderes escondidos, a sua flexibilidade e sua faculdade de adaptação extraordinária, tornando-se assim uma das ferramentas mais universais e das mais úteis em todos os setores da matemática"61. 0 primeiro gesto do matemático atual é ainda 0 traçado de um diagrama. É uma das razões que justificam a necessidade de estudar a relação entre diagrama e texto desde Euclides. 


\section{Notas e referências bibliográficas}

Gérard Émile Grimberg é professor adjunto do Instituto de Matemática da Universidade Federal do Rio de Janeiro. E-mail: gerard.emile@terra.com.br

1 Agradeço em primeiro lugar ao meu colega e amigo, Carlos H. B. Gonçalves (EACH-USP), que leu e releu o texto, estimulando-me pelas observações sempre pertinentes que me ajudaram na elaboração e na redação do texto. Agradeço também aos pareceristas da Revista Brasileira de História da Ciência, que me permitiram precisar a minha problemática e me ajudaram a corrigir o texto.

UNGURU, S. On the Need to Rewrite the History of Greek Mathematics. Archives for History of Exact Sciences, 15, p. 67-114, 1975.

3 NETZ, R. Introduction: The History of Early Mathematics - Ways of Re-Writing. Science in Context. Cambridge University Press, 16, 3, p. $275-286,2003$.

$4 \quad$ NETZ, op. cit., 2003, p. 278.

$5 \quad$ NETZ, R. The Shaping of Deduction in Greek Mathematics. Cambridge: Cambridge University Press, 2004.

6 MUGLER, C. Dictionnaire historique de la terminologie géométrique des grecs. Paris, 1958, p. 11.

7 MUGLER, op. cit., 1958, p. 14.

8 PROCLUS. A Commentary on the first Book of Euclid's Elements. Trad. angl. G. R. Morrow. Princeton: University Press, 1970.

9 BAILLY. Dictionnaire Grec Français. 26. ed. Paris: Hachette, 1963, p. 584 e 956.

10 PLATÃO. Republica. Trad. Leonel Vallandro. São Paulo: Edições de Ouro, 1966, p. 510-511; 264-265.

11 PLATÃO, op. cit. , 1966, 510 d-e, p. 264.

12 ARISTÓTELES. Órganon: Categorias, da interpretação, Analitícos anteriores, Analyticos posteriores, Tópicos, Refutações sofísticas. Trad. Edson Bini. 2.ed. São Paulo: Edipro, 2010, Anal. Post. I. 1. 71 a, I.10. 76 a.

13 ARISTÓtELES, op. cit., 2010, Anal. Post. II. 9. 10-18.

14 ARISTÓTELES. Retórica. Trad. Edson Bini. 2.ed. São Paulo: Edipro, 2011, 1410 b, 33-35.

15 ARISTÓTELES, op. cit., 2011, p. 238.

16 ARISTÓTELES. Poética. Trad. Edson Bini. 2.ed. São Paulo: Ed. Edipro, 2011, 17, 145 a, I. 23-25, p. 69.

17 ARISTÓTELES. Metafísica. Berlim: Becker, 1831, p. 1051, 0.1051 a 22 (tradução nossa). Cf. também, Metaphysique, site de Philippe Remacle, http:// remacle.org. (tradução nossa)

18 NETZ, op. cit. 2004, p. 36.

19 NETZ, op. cit. 2004, p. 36; seguindo KNORR, W. The Evolution of the Euclidean Elements. Dordrecht, 1975, p. 72.

20 PROCLUS, op. cit., 1970, p. 203-204.

21 EUCLIDES. Os Elementos. Trad. Bicudo. São Paulo: Unesp, 2009, p. 102.

22 EUCLID. The thirteen Books of Euclid's Elements. Trad. and com. T.L.Heath. London, 1908, p. 242.

23 NETZ, op. cit. 2004, p. 500.

24 PEIRCE, C. S., The Collected Papers of Charles Sanders Peirce. Electronic Edition, reproducing Vols. I-VI ed. Charles Hartshorne and Paul Weiss. Cambridge, MA: Harvard University Press, 1931-1935), Vols. VII-VIII ed. Arthur W. Burks (same publisher, 1958), p. 934. Disponível em: http://www.nlx.com/collections/95. (tradução nossa).

25 EUCLIDES, op. cit., 2009, p. 97.

26 SAITO, K. A preliminary study in the critical assessment of diagrams in Greek mathematical works. SCIAMVS - Sources and Commentaries in Exact Sciences, n. 7, 2006, p. 94.

27 ARISTÓTELES, op. cit., 2010, Anal. Ant., 41 b 13-23.

28 ARISTÓTELES, op. cit., 2010, Anal. Ant., 49 b 33.

29 AUTOLYCOS DE PITANE. La Sphère en mouvement. Levers et couchers héliaques. Testimonia. Trad. G. Aujac. Paris: Éd. Belles Lettres, 2002, p. 43.

30 Aqui não é o lugar para desenvolver uma teoria do ideograma. Utilizamos o termo como definido nos parênteses.

31 DESCARTES. Discurso do método, Regras para a direção do espirito. Trad. P. Nasseti. São Paulo: Matin Claret, 2005, Regras, IV, p. 81.

32 EUCLIDES, op. cit., 2009, p.102-103.

33 ARISTÓTELES, op. cit., 2010, Anal. Ant., 49 b-32-50 a 1, p. 229.

34 PROCLUS, op. cit., 1970, p. 207.

35 POINCARÉ, H. Dernières pensées. Paris: Flammarion, 1913, p. 59-60.

36 "Fique postulado traçar um reta de todo ponto até todo ponto", EUCLIDES, op. cit., 2009, p. 98.

37 "Também prolongar uma reta limitada, continuamente, sobre uma reta", Euclides, op. cit. 2009, Ibid.

38 "E que com qualquer centro e qualquer intervalo se descreva um círculo", seguindo a trad. de Comandino pelas razões avançadas por Bernard Vitrac em EUCLIDES. Les Éléments. Trad. Bernard Vitrac. Paris: PUF, 1990-2001, p. 169, n. 8.

39 C.f. tabela de Vitrac in Euclides, op. cit., 1990-2001, p. 517.

40 NETZ, op. cit., 2004. 
41 SAITO op. cit., 2006; SAITO, K. Les figures des Eléments dans les manuscrits et les éditions imprimées. Colloque "Traditions Euclidienne" 25-27 avril 2007, Clermont-Ferrand, Maison de la Recherche, France; SAITO, K. The Diagrams of Book IV of the Elements. In: Greek Manuscripts in Diagrams in Greek Mathematical Texts. Disponível em: http://www.hs.osakafu-u.ac.jp/ ken.saito/diagram/index.html.

42 HEIBERG JL; MENGE H (eds): Euclid: Stoicheia (The Elements). Euclidis opera omnia. Leipzig, Teubner, 1883-1916.

43 NETZ, op. cit., 2004, p. 83

44 SAITO, op. cit., 2006, 2007.

45 SAITO, op. cit., 2007, p. 9.

46 EUCLID, op. cit., 1908, v. I, p. 249.

47 MUGLER, op. cit., 1958, p. 7.

48 AUJAC, G. Le langage formulaire dans la géométrie grecque. Revue d'histoire des sciences, XXXVII/2, p. 97-109, 1984.

49 AUJAC, op. cit., 1984, p. 108.

50 AUTOLYCOS DE PITANE, op. cit., 2002, p. 25-26

51 NETZ, op. cit., 2004, p. 133-161.

52 GONÇALVES, C. H. B. Aspectos formulares da linguagem dos livros de VII a X. dos Elementos de Euclides. Revista Brasileira de História da Matemática, Especial, n. 1 - Festschrift Ubiratan D'Ambrosio, p. 281-298, dez., 2007.

53 NETZ, 2004 apud GONÇALVES, op. cit., 2007, p. 286.

54 GONÇALVES, op. cit., 2007, p. 292-295.

55 NETZ, R., op. cit., 2004, p. 253.

56 QUINTILIEN. Institutions oratoires. Paris: Bil. Panckoucke, 1832 , p. 9, 2, 40.

57 CICERON. De oratore. Livro II, LXXXVII. Disponível em: http://remacle.org/.

58 BERNARD, Alan. Ancient Rhetoric and Greek Mathematics: A Response to a Modern Historiographical Dilemma. Science in Context, 16, 3, 391-412, 2003. Cf. especialmente p. 406-410.

59 ARISTÓTELES, op. cit., 2011, 1404 a 9-14, p. 212-213.

60 ARISTÓTELES. Metafísica. Berlim: Becker, 1831, p. 1078a 33-1078b2.

61 DIEUDONNÉ, J. La domination universelle de la geometrie. In: SÉMINAIRE DE L'ÉCOLE NORMALE SUPÉRIEURE, 9 mars 1981, IREM de Paris Nord, 1982, p. 7. (tradução nossa)

[Recebido em Agosto de 2014. Aceito para publicação em Abril de 2015] 